Article

\title{
Analysis of the Threshold Effect of Financial Development on China's Carbon Intensity
}

\author{
Xiongfeng Pan, Yaobo Yan, Xiaoxue Peng and Qing Liu * \\ Faculty of Management and Economics, Dalian University of Technology, Dalian 116023, China; \\ xiongfengpan@dlut.edu.cn (X.P.); yanyaobodlut@163.com (Y.Y.); pandarxf@eyou.com (X.P.) \\ * Correspondence: liuqingdlut@126.com; Tel.: +86-411-8470-7990
}

Academic Editor: Marc Rosen

Received: 31 December 2015; Accepted: 10 March 2016; Published: 15 March 2016

\begin{abstract}
Using panel data on 30 provinces in China from 2005 to 2012, this paper conducts an empirical test on the threshold effect of the relationship between financial development and carbon emission intensity from the perspectives of financial scale and financial efficiency. The results show that at a low level of per capita GDP, the expansion of the financial scale and the enhancement of financial efficiency will increase carbon intensity. When the per capita GDP is greater than the threshold value (RMB 37,410), the expansion of the financial scale will also increase carbon intensity, but the potency of this effect will be weaker. At the same time, the improvement of financial efficiency will help reduce carbon intensity. Most provinces with per capita GDP greater than the threshold value (RMB 37,410) are located in the eastern coastal areas of China, whereas most provinces with per capita GDP less than the threshold value are located in the central and western areas of China. Both raising the level of openness and improving the industrial structure will have significantly positive effects on carbon intensity.
\end{abstract}

Keywords: carbon intensity; financial scale; financial efficiency; threshold effect

\section{Introduction}

For quite some time, China's energy consumption structure has given priority to coal. Consequently, all kinds of problems relating to carbon dioxide emissions have become increasingly serious there, in line with increased levels of consumption. Environmental degradation caused by the emission of greenhouse gases, such as carbon dioxide, is an important challenge especially with regards to both sustainable economic development and climate change control [1]. The optimization of energy production systems is a relevant issue that must be considered if China is to adhere to reduction policies for fossil fuel consumption and regulations on carbon dioxide emissions [2]. Not only does this phenomenon relate to China's economic and social development, it has also become a weak point in the international interest game [3]. As such, the rapid increase in carbon dioxide emissions has captured the attention of many researchers.

Financial development, as a key economic variable, can improve the economic efficiency of a country's financial system and affect both its economic behavior and energy demand. Financial development can also play an intermediary role in integrating social capital and in pushing enterprises to introduce advanced energy-saving technology and relevant management experience. Thus, financial development is likely to have a certain impact on carbon emissions. Scholars have conducted considerable research on the relationship between financial development and carbon emissions. Tamazian et al. [4] found that financial development reduced carbon dioxide emissions in Brazil, Russia, India, and China. Tamazian and Rao [5] analyzed the relationship between financial development and carbon emissions using panel data of 24 transition economies from 1993 to 2004, They found that financial development had an adverse effect on carbon emissions. Sadorsky [6] examined the effects 
of financial development on energy consumption in a sample of nine central and eastern European frontier economies, and the results indicated a positive and statistically significant relationship between financial development and carbon dioxide emissions when financial development was measured using banking variables, such as deposit money bank assets to GDP, financial system deposits to GDP, or liquid liabilities to GDP. Shahbaz et al. [7] analyzed the period of 1975Q1-2011Q4 in the case of Indonesia and found that financial development can reduce carbon dioxide emissions in all income group countries. In the same year, Shahbaz et al. [8] dealt with the question of whether financial development reduces carbon dioxide emissions in case of Malaysia, they revealed that financial development reduced carbon dioxide emissions for the Malaysian economy in the long term using the ARDL bound testing approach. Omri [9] estimated the three-way linkages among carbon dioxide emissions, energy consumption and economic growth using financial development as an instrumental variable and confirmed that financial development increased carbon dioxide emissions. Boutabba [10] examined the long-term equilibrium and the existence and direction of a causal relationship among carbon emissions, financial development, economic growth, energy consumption, and trade openness in India, and his results indicated that financial development had a long-term positive impact on carbon emissions, thereby implying that financial development improved environmental degradation. Ziaei [11] investigated the effects of financial indicator shocks, including credit and stock market shocks, on energy consumption and carbon dioxide using panel vector auto-regression models, and he founded that the associations between financial development variables and carbon dioxide emissions were driven by feedback and growth hypothesis. Meanwhile, Al-mulali et al. [12] also investigated the effects of energy consumption and carbon dioxide emissions on GDP growth and financial development in 30 Sub Saharan African countries, energy consumption and carbon dioxide emissions were found to have a positive causal relationship on GDP growth and financial development. Zhang [13] used cointegration theory, the Granger causality test and variance decomposition to explore the influence of financial development on carbon emissions, and his results indicated that China's financial development acts as an important driver for carbon emissions increase. Salahuddin et al. [14] investigated the relationship between carbon dioxide emissions, economic growth, electricity consumption and financial development in the Gulf Cooperation Council (GCC) countries using panel data for the period of 1980-2012, and they revealed that there is no causal link between financial development and carbon emissions. Abbasi and Riaz [15] explored the influence of economic and financial development on carbon emissions in a small emerging economy using the augmented VAR approach, and $\mathrm{CO}_{2}$ emissions were found to cointegrate with financial development indicators.

From the aforementioned literature, we see that scholars have achieved a certain level of progress in the field of the effect of financial development on carbon emission, but some questions still require further exploration. First, previous studies have ignored the nonlinear relationship between financial development and carbon emissions because of the differences among China's provinces in terms of economic development level and industrial structure, leading to differential effects between financial development and carbon emissions. Second, previous research has considered financial scale as a single measure of financial development to study the effects of financial development on energy efficiency. In fact, financial development is a function of the financial system, which should be considered as an entire process of dynamic optimization, including the expansion of financial scale and the enhancement of financial efficiency. Thus, the combination of these two aspects constitutes the entire point of financial development. Hence, we will divide financial development into two components, namely financial scale and efficiency, and use a panel threshold model to test the relationship between financial development and carbon emission, Doing so will help provide convincing evidence that finance supports low-carbon development. This paper contributes to the literature in two ways. First, we use the threshold regression model proposed by Hansen to test whether there is a nonlinear relationship between financial development and carbon intensity, and find that there is not a simple linear relationship between financial development and carbon intensity, but rather a subsectional 
threshold relationship divided by per capita GDP. Second, we examine the nonlinear relationship between financial development and carbon emissions from the perspectives of financial scale and financial efficiency based on the dynamic optimization of the overall function of the financial system, and find that at a low level of per capita GDP, the expansion of financial scale and the enhancement of financial efficiency will both increase carbon intensity. When per capita GDP is greater than the threshold value (RMB 37,410), the expansion of the financial scale will also increase carbon intensity, but the potency of this effect will be comparatively weaker. Our research may help to better understand how to effectively use the role of finance in reducing the carbon intensity and provide a realistic basis for formulating financial policies.

This paper is organized as follows: Section 2 introduces model specification, variable selection and data sources. Section 3 studies the threshold effect of financial development on China's carbon intensity. Finally, conclusions and suggestions are proposed in Section 4.

\section{Model Specification, Variables Selection and Data Sources}

\subsection{Model Specification}

This study focuses on the impact of financial scale and financial efficiency on carbon intensity. Considering that carbon emission can also be influenced by a series of non-financial factors, we introduce the level of openness and industrial structure as control variables. Thus, we define the basic linear model as follows:

$$
\ln Q_{i t}=\mu_{i}+\alpha_{1} \ln F D_{i t}+\alpha_{2} \ln F E_{i t}+\beta_{1} \ln O P E N_{i t}+\beta_{2} \ln I N D_{i t}+\varepsilon_{i t}
$$

where $Q_{i t}$ is the carbon intensity, the core explanatory variables, $F D_{i t}$ and $F E_{i t}$ represent financial scale and financial efficiency, respectively, OPEN $N_{i t}$ is the level of openness, and $I N D_{i t}$ is industrial structure. Moreover, the subscript $i$ and $t$ represent the region and time, respectively.

To examine the nonlinear threshold effect between financial development and carbon emissions, we adopt the threshold regression model developed by Hansen [16]. This model can avoid the disadvantages inherent in the traditional threshold model and has the following advantage: first, it does not need to set the nonlinear equations; second, the number of the threshold is totally determined endogenously by the sample data; third, it will calculate the confidence interval of parameters according to the asymptotic distribution theorem; four, it will estimate the statistical significance using the bootstrap method. Considering that the influence of financial development on carbon emission intensity is constrained by the level of economic development, the basic model is extended to the multiple threshold model with the level of economic development acting as the threshold. Thus, the multiple threshold model is described as follows:

$$
\begin{aligned}
& \ln Q_{i t}=\mu_{i}+\alpha_{11} \ln F D_{i t}\left(\ln P G D P_{i t} \leqslant \gamma_{1}\right)+\alpha_{12} \ln F D_{i t}\left(\gamma_{1}<\ln P G D P_{i t} \leqslant \gamma_{2}\right) \\
& +\cdots+\alpha_{1, n-1} \ln F D_{i t}\left(\gamma_{n-1}<\ln P G D P_{i t} \leqslant \gamma_{n}\right)+\alpha_{1, n} \ln F D_{i t}\left(\gamma_{n}<\ln P G D P_{i t}\right) \\
& +\alpha_{21} \ln F E_{i t}\left(\ln P G D P_{i t} \leqslant \gamma_{1}\right)+\alpha_{22} \ln F E_{i t} \cdot I\left(\gamma_{1}<\ln P G D P_{i t} \leqslant \gamma_{2}\right)+\cdots \\
& +\alpha_{2, n-1} \ln F E_{i t}\left(\gamma_{n-1}<\ln P G D P_{i t} \leqslant \gamma_{n}\right)+\alpha_{2, n} \ln F E_{i t}\left(\gamma_{n}<\ln P G D P_{i t}\right) \\
& +\beta_{1} \ln O P E N_{i t}+\beta_{2} \ln I N D_{i t}+\varepsilon_{i t}
\end{aligned}
$$

where $\mathrm{p}^{G D P}$ is the threshold variable, which represents the level of regional economic development, $\gamma_{1}, \gamma_{2}, \gamma_{n-1} \ldots \gamma_{n}$ are the values of the threshold variables, and $\alpha_{11}, \alpha_{12}, \alpha_{2, n-1} \ldots \alpha_{2, n}$ are the estimated coefficients of the threshold variables. Moreover, we adopt the fixed effects model to assume that each sample individual, $\mu_{i}$ is independent identically distributed, such that every individual has its own fixed and unique intercept to express the unique qualities of every observation, in so doing, we reduce 
the covariation coefficient and enhance the validity of the estimated results. The coefficient matrix and variable matrix, respectively, are $\beta$ and $\chi$ :

$$
\beta=\left|\begin{array}{c}
\alpha_{11} \\
\alpha_{12} \\
\vdots \\
\alpha_{1, n} \\
\alpha_{21} \\
\alpha_{22} \\
\vdots \\
\alpha_{2, n} \\
\beta_{1} \\
\beta_{2}
\end{array}\right|, \chi=\left|\begin{array}{c}
\ln F D_{i t}\left(\ln P G D P_{i t} \leqslant \gamma_{1}\right) \\
\ln F D_{i t}\left(\gamma_{1}<\ln P G D P_{i t} \leqslant \gamma_{2}\right) \\
\vdots \\
\ln F D_{i t}\left(\gamma_{n}<\ln P G D P_{i t}\right) \\
\ln F E_{i t}\left(\ln P G D P_{i t} \leqslant \gamma_{1}\right) \\
\ln F E_{i t}\left(\gamma_{1}<\ln P G D P_{i t} \leqslant \gamma_{2}\right) \\
\vdots \\
\ln F E_{i t}\left(\gamma_{n}<\ln P G D P_{i t}\right) \\
\ln O P E N_{i t} \\
\ln I N D_{i t}
\end{array}\right|
$$

Therefore, Equation (2) can be transformed into following function:

$$
\ln Q_{i t}=\beta^{T} \chi_{i t}(\gamma)+\mu_{i}+\varepsilon_{i t}
$$

The above function in matrix form is:

$$
Y^{*}=\chi(\gamma)^{* T} \beta+e *
$$

The coefficient for the limited variable is $\beta$ :

$$
\beta_{\gamma}=\left(\chi^{*}(\gamma)^{T} \chi^{*}(\gamma)\right)^{-1} \chi^{*}(\gamma)^{T} Y^{*}
$$

The residual for the regression function is:

$$
e^{*}(\gamma)=Y^{*}-\chi^{*}(\gamma) \beta_{\gamma}^{T}
$$

The residual square sum for the regression function is:

$$
\operatorname{SSE}(\gamma)=e^{*}(\gamma)^{T} e^{*}(\gamma)=\gamma^{* T}\left[1-\chi^{*}(\gamma)^{T}\left(\chi^{*}(\gamma)^{T} \chi^{*}(\gamma)\right)^{-1} \chi^{*}(\gamma)^{T}\right] Y^{*}
$$

where the threshold point can be estimated as follows:

$$
\hat{\gamma}=\underset{\gamma}{\operatorname{argmin} S S E_{1}}(\gamma)
$$

\subsection{Variables and Data}

\subsubsection{Explained Variable}

Carbon intensity is a measure of unit GDP carbon emission. A two-step calculation is performed as the data of carbon emissions cannot be directly obtained from the statistical yearbook. First, we collect the energy consumption values of various areas within China and the conversion coefficients of various energy types into standard coal. Then, all energy types are converted into the standard measure of heat energy in China, known as standard coal. Carbon emissions are calculated according to IPCC Carbon Emissions Calculation Guide using the following formula $[17,18]$.

$$
C=\sum_{j} E_{j} \times \delta_{j}
$$


where $C$ is the carbon emissions, $E_{j}$ is the consumption of energy $j$, and $\delta_{j}$ is the conversion coefficient of energy j. Based on IPCC National Greenhouse Gas Emission Inventory Guidebook, we obtain the carbon emission conversion coefficient of various energy types (Table 1).

Table 1. Carbon emission coefficient of different sources of energy (unit: tc/tce).

\begin{tabular}{cccc}
\hline Energy & Carbon Emission Coefficient & Energy & Carbon Emission Coefficient \\
\hline Raw Coals & 0.7559 & Kerosene & 0.5714 \\
Cokes & 0.8550 & Diesel oils & 0.5921 \\
Crude oils & 0.5857 & Fuel oils & 0.6185 \\
Gasoline & 0.5538 & Natural gas & 0.4483 \\
\hline
\end{tabular}

Using the carbon emissions coefficient and the calculation formula of carbon emission, we obtain the carbon emissions of the 30 Chinese provinces. Then, we then obtain the corresponding carbon intensity of each province by dividing those values by each province's GDP. In this way, carbon emission and carbon intensity are determined.

\subsubsection{Core Explanatory Variables}

As mentioned above, financial development involves the expansion of financial scale and the enhancement of financial efficiency. Therefore, we use financial scale and financial efficiency to measure the level of financial development.

(1) Financial scale

Generally speaking, the Mckinnon Index and Goldsmith index are the most popular indexes used to measure financial scale; however, because China's regional financial assets and M2 (Broad money) statistics cannot be obtained from previous statistical data, we cannot use the Mckinnon Index and Goldsmith index to calculate financial scale in the paper. Thus, we use the deformation of Goldsmith index with deposits and loans used in place of financial assets, based on this, we use the proportion of deposits and loans in GDP to measure financial scale.

(2) Financial efficiency

We use the proportion of non-state enterprises' loans in GDP to measure financial efficiency. Presently, there are a large number of policy-oriented loans and non-performing loan in China's banking sector, and most of the credit resources are allocated to the state sector; indeed, less than $30 \%$ of the bank loans flow to the non-state sector. Meanwhile, the contribution of the non-state sector to the GDP is about 65\% [19], and so the proportion of non-state enterprises' loans in total loans can better measure the efficiency of China's financial system.

Because China's existing statistical yearbooks do not list the values of non-state enterprises' loans, we estimate this indicator based on the method developed by Zhao [20]. We assume that the proportion of state-owned enterprises' loans in total loans and the proportion of state-owned enterprises' fixed assets in the whole society constitute a fixed proportion $\beta$. Then, "Total loans/GDP" can be decomposed and expressed as:

$$
\begin{aligned}
& \frac{\text { Total loans }}{\text { GDP }}=\frac{\text { State }- \text { owned enterprises }}{\text { ' loans }}+\frac{\text { Nonstate }- \text { owned enterprises }}{\text { ' loans }} \\
& =\beta \frac{\text { Total loans }}{\text { GDP }} \cdot \frac{\text { State }- \text { owned enterprise fixed assets investment }}{\text { Total fixed assets investment }}+ \\
& \frac{\text { Non }- \text { state enterprises' loan }}{\text { GDP }}
\end{aligned}
$$

Then, we estimate the value of $\beta$ based on the fixed effect. In this way, we obtain the value of financial efficiency. 


\subsubsection{Threshold Variable}

Because the effect of financial development on carbon intensity is restricted by the level of economic development, we select per capita GDP (PGDP) as the threshold variable of carbon intensity affected by financial development.

\subsubsection{Control Variables}

(1) The level of openness

Considering that improving the level of openness is helpful to obtain advanced technology and management experience related to carbon reduction, we introduce the level of openness as one of the control variables in this paper. We mainly use the proportion of total value of imports and exports in GDP as the index to measure the level of openness [21].

(2) Industrial Structure

China is in a critical period of industrial structure transformation and adjustment. Because various industries' demand for energy is different, carbon emissions also differ in different industries. Therefore, we introduce industrial structure as another control variable, and it is measured by the share of added value of the tertiary industry in GDP.

\subsection{Data Sources}

Given the lack of relative data in Tibet, Hong Kong, Macau and Tainwan, we select the other 30 provinces as the research objective, and the study period is from 2005 to 2012. The data come from China Statistical Yearbook and China Energy Statistical Yearbook. Table 2 shows the descriptive statistics for the aforementioned variables. Among all the variables, the maximum values are much larger than the minimum values, indicating that there are huge heterogeneities across provinces in China.

Table 2. Descriptive statistics of variables $(\mathrm{N}=240)$.

\begin{tabular}{lccccc}
\hline Variable & Definitions and Measures & Mean & Std. Dev & Min & Max \\
\hline$F D$ & total deposits and loans/GDP & 2.51 & 1.04 & 1.02 & 7.30 \\
$F E$ & non-state enterprises' loans/GDP & 0.58 & 0.34 & 0.05 & 2.05 \\
PGDP & GDP/population & $28,895.05$ & $18,242.11$ & 5052 & 93,173 \\
OPEN & total value of imports and exports/GDP & 4.61 & 5.29 & 0.61 & 22.91 \\
$I N D$ & added value of the tertiary industry/GDP & 40.28 & 7.79 & 22.49 & 75.9 \\
\hline
\end{tabular}

\section{Empirical Results and Analysis}

\subsection{Regional Carbon Intensity Measurement}

We can calculate the carbon intensity values of 30 provinces in China from 2005 to 2012 according to Equation (10), and the results are listed in Table 3.

Table 3 indicates that the lowest carbon intensity values are found in the provinces of Beijing, followed by Guangdong and Shanghai. Two of the highest scoring provinces with respect to carbon intensity are Shanxi and Ningxia, and both of these two provinces obtain average carbon intensity values greater than 4.0 on average throughout the observed period. Regarding the regional distribution of carbon intensity in China, the eastern region has the lowest carbon intensity value and has an average carbon intensity value of 0.98 for the 8 years period. The central region has an average carbon intensity value of 1.54 during this period. Finally, the western region reports the highest carbon intensity value at 1.88. Clearly, carbon intensity in China increases as one moves inland from the coast. The reason for this may be related to geographical location and industrial structure. On one hand, most of the lower-carbon-intensity provinces are located in the eastern coastal region, which allows them to obtain the abundant capital, management personnel, technology and informational to improve 
their carbon intensity levels. In contrast, the distance from the inland areas to the coastal areas hinders the transfer of the advanced technology, capital and management [22]. These factors make the comprehensive level of carbon intensity in the central and western regions relatively higher. On the other hand, those regions with lower levels of carbon intensity also contain most of the areas that have more highly developed industrial structures and markets. Since the implementation of the "Reform and Opening" process, Beijing, Shanghai, Guangdong, Fujian and other coastal areas have gradually implemented the "going out" strategy, which has contributed to the adjustment and optimization of the industrial structure under an export-oriented economy. At the same time, these areas have established a highly standardized market system, and this has helped transit them away from resource-oriented economic growth. The level of industrial development in the west of the country is low and the basic industries are resource-oriented. Given the development of electric power, coal mining, oil and other specialized industries, the technological development in these areas is relatively poor [23]. Moreover, the high levels of carbon intensity in these areas have remained unchanged. We can also see that the carbon intensity of all the provinces in China have exhibited a downward trend in recent years, this indicates that China's implementation of an energy reduction strategy has resulted in substantial improvements [24].

Table 3. Carbon Intensity of 30 provinces in China from 2005 to 2012.

\begin{tabular}{|c|c|c|c|c|c|c|c|c|}
\hline Province & 2005 & 2006 & 2007 & 2008 & 2009 & 2010 & 2011 & 2012 \\
\hline $\mathrm{Al}_{\mathrm{s}}$ & 0144 & 36451 & 1.18958 & 10726 & 1.09397 & 0.93355 & 0.82782 & 0.82952 \\
\hline Beijing & 45569 & 55252 & 0.40509 & 30330 & 0.24163 & 0.20096 & .15946 & \\
\hline Chongqing & 92751 & 0.94415 & 0.88350 & 0.91987 & 0.81199 & 0.68926 & 0.59926 & 0.50667 \\
\hline Fujian & 35363 & 0.75283 & 0.64638 & 0.55118 & 0.53103 & 0.44041 & 0.44747 & 0.38235 \\
\hline Gansu & 94534 & 2.38405 & 1.89134 & 1.45327 & 1.21831 & 1.15519 & 1.07602 & 0.99637 \\
\hline Guangdong & 55875 & 0.62128 & 0.48035 & 0.39150 & 0.33149 & 0.30708 & 0.29690 & 0.26403 \\
\hline Guangxi & 54945 & 0.87817 & 0.75054 & 0.59102 & 0.58898 & 0.55827 & 0.50909 & 0.47836 \\
\hline Guizhou & 64512 & 3.66069 & 3.31357 & 2.63333 & 2.51270 & 2.25590 & 1.92486 & 1.72932 \\
\hline Hainan & .88460 & 1.35323 & 0.87482 & 0.59004 & 0.47646 & 0.38644 & 0.35660 & 0.33750 \\
\hline Hebei & 79879 & 1.88391 & 1.67803 & 1.45819 & 1.41319 & 1.33529 & 1.21284 & 1.16001 \\
\hline Heilongjiang & 05115 & 1.88093 & 1.56659 & 1.37631 & 1.30290 & 1.20932 & 1.06992 & 1.02311 \\
\hline Henan & 08490 & 1.64873 & 1.49686 & 1.22878 & 1.24076 & 1.07015 & 1.03017 & 0.87761 \\
\hline Hubei & 06157 & 1.21532 & 1.01270 & 0.78297 & 0.72211 & 0.67893 & 0.63750 & 0.56490 \\
\hline Hunan & 76974 & 1.11964 & 0.98802 & 0.75378 & 0.67246 & 0.58974 & 0.53322 & 0.46501 \\
\hline Jiangsu & 79411 & 0.90178 & 0.73042 & 0.59991 & 0.53069 & 0.48686 & 0.47395 & 0.42985 \\
\hline Jiangxi & 19 & 0.97760 & 0.85529 & 0.72204 & 0.60309 & 0.56739 & 0.50250 & 4278 \\
\hline Jilin & & 1.79084 & 1.41156 & 1.17851 & 1.07422 & 1.00141 & 0.95807 & 0.85643 \\
\hline Liaoning & 08184 & 2.33665 & 1.66361 & 1.21257 & 1.05876 & 0.89305 & 0.77241 & 0.69305 \\
\hline InnerMongolia & 18939 & 2.95333 & 2.57666 & 2.47261 & 2.10918 & 1.44130 & 2.22740 & 2.09400 \\
\hline & & & 4.81474 & 4.15534 & 3.81109 & 3.63708 & 3.80199 & 3.18811 \\
\hline nai & 126 & 255 & 1.30848 & 1.29453 & 1.27534 & 0.99087 & 1.05624 & 1.10665 \\
\hline Shaanxi & 4.69738 & 1.94276 & 1.49322 & 1.23163 & 1.09761 & 1.04334 & 0.93498 & 0.96286 \\
\hline Shandong & 3.18005 & 1.56106 & 1.29938 & 1.04829 & 0.97823 & 0.88589 & 0.80216 & 0.74262 \\
\hline Shar & 2.06268 & 0.74217 & 0.53883 & 0.43768 & 0.36669 & 0.33923 & 0.30380 & 0.27157 \\
\hline anxi & 5.49681 & 5.47125 & 4.77691 & 3.90441 & 3.65558 & 3.18935 & 3.01833 & 3.11805 \\
\hline Sichuan & 1.18163 & 0.93797 & 0.86237 & 0.79653 & 0.77306 & 0.62439 & 0.51413 & 0.47465 \\
\hline Tianjin & 3.06597 & 1.14203 & 0.88543 & 0.65727 & 0.55751 & 0.48651 & 0.42497 & 0.38496 \\
\hline Xinjiang & 7.09467 & 2.32796 & 1.75726 & 1.43981 & 1.62031 & 1.35691 & 1.32471 & 1.40170 \\
\hline Yunnan & 1.75297 & 1.72786 & 1.50856 & 1.30605 & 1.28461 & 1.15867 & 0.98748 & 0.88904 \\
\hline Zhejiang & 1.92510 & 0.85781 & 0.70277 & 0.57596 & 0.52612 & 0.44134 & 0.39420 & 0.35477 \\
\hline East & 2.92375 & 1.15503 & 0.90046 & 0.71145 & 0.63744 & 0.56392 & 0.51316 & 0.46914 \\
\hline Central & 2.78998 & 1.93360 & 1.66219 & 1.38176 & 1.29564 & 1.15498 & 1.07219 & 1.02218 \\
\hline West & 3.71664 & 2.22159 & 1.92366 & 1.66309 & 1.55484 & 1.35556 & 1.35965 & 1.25707 \\
\hline China & 3.17880 & 1.75372 & 1.47876 & 1.23913 & 1.14934 & 1.01180 & 0.97261 & 0.90552 \\
\hline
\end{tabular}




\subsection{Multi-Collinearity Test and Stationary Test}

\subsubsection{Multi-Collinearity Test}

Considering that we introduce numerous explanatory variables in the econometric model, we carry on the multi-collinearity test to assess whether there is a multi-collinearity between explanatory variables. The results are shown in Table 4 . It can be seen from Table 4 that the VIF value of each variable is below 10 , that is to say, there is no multi-collinearity among all explanatory variables.

Table 4. Results of the multi-collinearity test.

\begin{tabular}{ccccc}
\hline Variable & $\operatorname{lnFD}$ & $\operatorname{lnFE}$ & $\operatorname{lnOPEN}$ & $\operatorname{lnIND}$ \\
\hline $\ln \mathrm{FD}$ & 1 & & & \\
$\operatorname{lnFE}$ & 0.3690 & 1 & & \\
$\ln \mathrm{NPEN}$ & 0.4676 & 0.3495 & 1 & \\
$\operatorname{lnIND}$ & 0.5128 & 0.2277 & 0.3624 & 1 \\
VIF value & 1.63 & 1.21 & 1.38 & 1.39 \\
\hline \multicolumn{4}{l}{ Note: the above results are getted using command "estat vif" in stata13. }
\end{tabular}

\subsubsection{Stationary Test}

Because we will conduct the empirical analysis using panel data method, it is necessary to carry out a stationary test on each variable. Given that this empirical research works on 30 provinces of China, the presence of cross-section dependence (CD) is probable [25]. We therefore first use Pesaran (2004) CD test to assess the cross-section dependence of each variable, and the results are shown in Table 5.

Table 5. Results of CD test.

\begin{tabular}{ccccc}
\hline \multirow{2}{*}{ Variable } & \multicolumn{4}{c}{ Lag Order } \\
\cline { 2 - 5 } & $\mathbf{0}$ & $\mathbf{1}$ & $\mathbf{2}$ & $\mathbf{3}$ \\
\hline $\ln \mathrm{T} D$ & $36.167^{* * *}$ & $34.943^{* * *}$ & $15.787^{* * *}$ & $6.501^{* * *}$ \\
$\operatorname{lnFE}$ & $52.533^{* * *}$ & $47.726^{* * *}$ & $29.263^{* * *}$ & $18.054^{* * *}$ \\
$\ln \mathrm{C}$ & $21.037^{* * *}$ & $9.707^{* * *}$ & $0.115^{*}$ & $0.665^{*}$ \\
$\ln \mathrm{PGDP}$ & $6.912^{* * *}$ & $3.130^{* * *}$ & $3.382^{* * *}$ & $0.761^{*}$ \\
$\operatorname{lnOPEN}$ & $38.268^{* * *}$ & $38.268^{* * *}$ & $31.226^{* * *}$ & $28.829^{* * *}$ \\
$\operatorname{lnIND}$ & $25.109^{* * *}$ & $13.263^{* * *}$ & $13.263^{* * *}$ & $16.422^{* * *}$ \\
\hline
\end{tabular}

Note: $(1)^{* * *}{ }^{* *}$ and ${ }^{*}$ denote rejection of the null hypothesis at the $1 \%, 5 \%$ and $10 \%$ levels, respectively; $(2)$ The cross regressions include both the constant and trend as deterministic components; (3) the above results are getted using command "xtcsd" in stata 13.

The results in Table 5 indicate that the null hypothesis of cross-section independence is rejected at different lag orders, and this provides strong evidence of the existence of the cross sectional dependence among all the variables of 30 provinces. We should therefore use a Pesaran (2007) panel unit root test (CIPS) to assess the existence of the unit root [26]. Tthe results are shown in Table 6. It can be seen from Table 6 that not all of the variables can refuse the unit root assumption. That is to say, all of the variables are stationary. 
Table 6. Results of CIPS test.

\begin{tabular}{ccccccc}
\hline Variable & $\operatorname{lnFD}$ & $\operatorname{lnFE}$ & $\ln Q$ & $\ln P G D P$ & $\operatorname{lnOPEN}$ & $\operatorname{lnIND}$ \\
\hline CIPS & $-2.673^{*}$ & $-3.059^{* * *}$ & $-3.067^{* * *}$ & $-2.256^{* * *}$ & $-3.352^{* * *}$ & $-4.391^{* * *}$
\end{tabular}

Note: (1) ***,** and * denote rejection of the null hypothesis at the $1 \%, 5 \%$ and $10 \%$ levels, respectively; (2) The Akaike information criterion (AIC) is used in selecting the lag lengths; (3) The cross regressions include both the constant and trend as deterministic components; (4) the above results are getted using command "pescadf" in stata13.

\subsection{Panel Threshold Effect Test}

\subsubsection{Panel Threshold Effect Test}

Hansen used the bootstrap method to find the number of threshold according to the principle of the minimum residual sum of squares. He successively conducted the significance test on the number of thresholds. Thus, we adopt the bootstrap method to conduct the threshold effect test. Table 7 shows the results.

Table 7. Results of threshold effect test.

\begin{tabular}{cccc}
\hline Hypothesis Test & LR $\mathbf{( 0 \%} \mathbf{5 \%} \mathbf{1} \mathbf{1 \%}$ Critical Points) & F & p \\
\hline $\begin{array}{c}\text { H0:No threshold; } \\
\text { H1:Single threshold }\end{array}$ & $7.3523(4.4754,5.9906,8.9557)$ & 30.2544 & 0.0000 \\
\hline $\begin{array}{c}\text { H0: Single threshold; } \\
\text { H1:Double-threshold }\end{array}$ & $9.1527(5.1598,6.6852,9.3089)$ & 18.5894 & 0.0000 \\
\hline $\begin{array}{c}\text { H0: Double-threshold; } \\
\text { H1:Triple-threshold }\end{array}$ & $11.1324(5.2659,7.1286,10.7881)$ & 6.6683 & 0.0630 \\
\hline
\end{tabular}

Note: (1) the frequency of bootstrap is 1000; (2) the above results are getted using command "xthreg" in stata13.

In Table 7, it can be seen that both the single-threshold model and double-threshold model of the two core explanatory variables pass the significance test at the confidence level of $1 \%$. In contrast, the triple-threshold model does not pass the significance test at the confidence level of $5 \%$. However, the $95 \%$ confidence intervals in Table 8 show that the confidence interval of the double-threshold is contained in the single-threshold, so we select the single-threshold model. According to Table 8, lnPGDP, the value of the threshold variable, is 10.5297, therefore the value of per capita GDP is RMB 37,410.

Table 8. The values of thresholds and the confidence interval.

\begin{tabular}{ccc}
\hline Model & Estimated Value of Threshold & 95\% Confidence Interval \\
\hline Single-threshold Model & 10.5297 & $(9.8660,11.1324)$ \\
Double-threshold Model & 10.3118 & $(10.2635,10.8349)$ \\
\hline
\end{tabular}

Note: the above results are getted using command "xthreg" in stata13.

Based on the results of the aforementioned tests and analyses, we will use the linear model and single-threshold model to analyze the relationship between financial development and carbon intensity. We use the level of economic development as the threshold variable to study the influence of financial scale and financial efficiency on carbon intensity; as is shown in Table 9, the influence of the level of economic development on carbon intensity exhibits a significant single threshold effect. 
Table 9. Results of linear model and single-threshold model.

\begin{tabular}{|c|c|c|c|}
\hline Variable & Linear Model & Variable & Single-Threshold Model \\
\hline \multirow[t]{2}{*}{$\operatorname{lnFD}$} & \multirow{2}{*}{$\begin{array}{c}0.9482 * * * \\
(4.4059)\end{array}$} & $\operatorname{lnFD}(\ln P G D P<10.5297)$ & $\begin{array}{c}1.6455^{* * *} \\
(6.0460)\end{array}$ \\
\hline & & $\operatorname{lnFD}(\ln P G D P \geqslant 10.5297)$ & $\begin{array}{l}0.5573 * \\
(1.6813)\end{array}$ \\
\hline \multirow[t]{2}{*}{$\operatorname{lnFE}$} & \multirow{2}{*}{$\begin{array}{c}-0.8283^{* * *} \\
(-4.0871)\end{array}$} & $\operatorname{lnFE}(\operatorname{lnPGDP}<10.5297)$ & $\begin{array}{c}0.8645^{* * *} \\
(4.1699)\end{array}$ \\
\hline & & $\operatorname{lnFE}(\operatorname{lnPGDP} \geqslant 10.5297)$ & $\begin{array}{c}-0.8446^{* * *} \\
(-4.3830)\end{array}$ \\
\hline $\operatorname{lnOPEN}$ & $\begin{array}{l}-0.2022^{* * *} \\
(-4.4795)\end{array}$ & $\operatorname{lnOPEN}$ & $\begin{array}{l}-0.2184^{* * *} \\
(-4.8296)\end{array}$ \\
\hline $\operatorname{lnIND}$ & $\begin{array}{l}-1.3732 * * * \\
(-4.6436)\end{array}$ & $\operatorname{lnIND}$ & $\begin{array}{l}-1.3114^{* * *} \\
(-4.6240)\end{array}$ \\
\hline Hausman Test & $23.78^{* * *}$ & & \\
\hline
\end{tabular}

Note: $(1)^{* * *}, * *$ and $*$ denote rejection of the null hypothesis at the $1 \%, 5 \%$ and $10 \%$ levels, respectively; (2) hausman test results show that the fixed effects model is selected; (3) the results of Linear Model is getted using command "xtreg" in stata13; (4) the results of Single-threshold Model is getted using command "xthreg" in stata13.

\subsubsection{Analysis of the Core Explanatory Variables}

According to the estimated results of single-threshold model (Table 9), the effects of carbon intensity influenced by financial scale and financial efficiency can be obtained as shown in Figure 1.

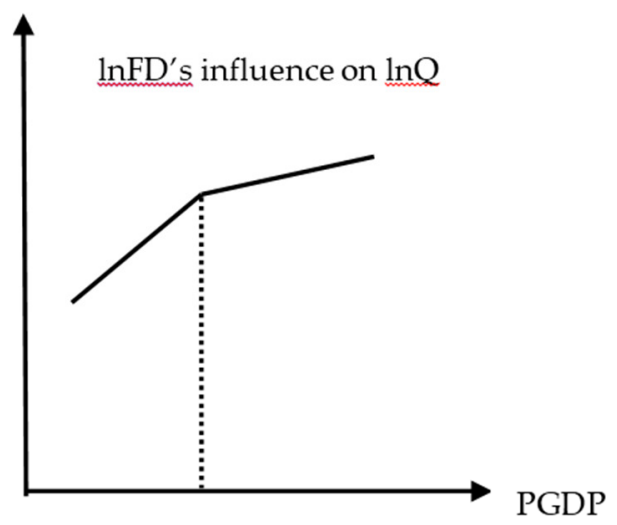

37410

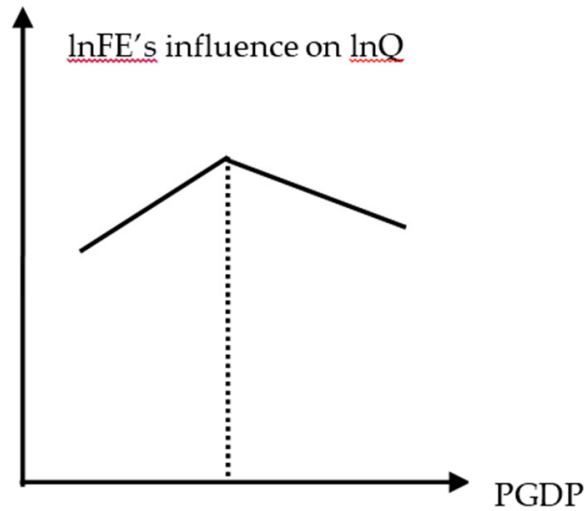

37410

Figure 1. The threshold effect of financial development to carbon intensity.

The following can be seen in Figure 1:

(1) The direction of the effect of financial scale on carbon intensity before and after the threshold value does not change, but the influence degree does decreases beyond the threshold value. That is to say, the expansion of financial scale will increase carbon intensity, but the promotion effect becomes weaker upon reaching the threshold value.

(2) The direction of financial efficiency before and after the threshold value changes significantly, when the threshold value is not reached, the enhancement of financial efficiency will increase carbon intensity, while upon reaching the threshold, it will prompt the reduction in carbon intensity. 


\subsubsection{Analysis of the Threshold Variable}

Based on the level of economic development and its value compared to the threshold value in each region, we divide the provinces into two zones. The low zone has per capita GDP that is lower than the threshold value, and the high zone has per capita GDP greater than the threshold value during the observation period. As Table 10 shows, 14 provinces, such as Shanghai, Beijing, Tianjin, Jiangsu, Zhejiang, Guangdong, Inner Mongolia, Shandong, Liaoning, Fujian, Jilin, Chongqing, Hubei, and Shaanxi, belong to the high zone. Most of these provinces that belong to the high zone are located in the eastern coastal areas, whereas the less developed provinces located in the Central and Western areas mainly belong to the low zone, in which the expansion of financial scale and the enhancement of financial efficiency will increase carbon intensity.

Table 10. The threshold values of carbon intensity compared with regional GDP.

\begin{tabular}{|c|c|c|}
\hline Year & Low Zone(GDP per Capita $<37,410$ yuan) & High Zone(GDP per Capita $>37,410$ yuan) \\
\hline 2005 & $\begin{array}{l}\text { Guizhou, Gansu, Yunnan, Anhui, Guangxi, } \\
\text { Sichuan, Jiangxi, Shaanxi, Qinghai, Ningxia, } \\
\text { Hunan, Hainan, Chongqing, Henan, Hubei, } \\
\text { Shanxi, Jilin, Heilongiang, Hebei, Inner } \\
\text { Mongolia, Fujian, Liaoning, Shandong, } \\
\text { Guangodng, Jiangsu, Zhejiang, Tianjin }\end{array}$ & Beijing, Shanghai \\
\hline 2009 & $\begin{array}{l}\text { Guizhou, Gansu, Yunnan, Anhui, Guangxi, } \\
\text { Sichuan, Jiangxi, Hainan, Qinghai, Xinjiang, } \\
\text { Hunan, Henan, Hebei, Shanxi, Ningxia, } \\
\text { Heilongjiang, Chongqing, Jilin, Fujian, } \\
\text { Liaoning, Shandong, Shaanxi }\end{array}$ & $\begin{array}{l}\text { Inner Mongolia, Guangdong, Zhejiang, } \\
\text { Jiangsu, Tianjin, Beijing, Shanghai }\end{array}$ \\
\hline 2012 & $\begin{array}{l}\text { Guizhou, Gansu, Yunnan, Anhui, Guangxi, } \\
\text { Sichuan, Jiangxi, Hainan, Qinghai, Xinjiang, } \\
\text { Hunan, Henan, Hebei, Shanxi, Ningxia, } \\
\text { Heilongjiang }\end{array}$ & $\begin{array}{l}\text { Shanghai, Beijing, Tianjin, Jiangsu, Zhejiang, } \\
\text { Guangdong, Inner Mongolia, Shandong, } \\
\text { Liaoning, Fujian, Jilin, Chongqing, Hubei, } \\
\text { Shaanxi }\end{array}$ \\
\hline
\end{tabular}

\subsubsection{Analysis of the Control Variables}

Table 9 also shows that the level of openness and industrial structure each has a significant negative relationship with carbon intensity; specifically, by raising the level of openness and improving the industrial structure, a region can significantly reduce the carbon intensity. The level of openness increasing by $1 \%$ reduces to the carbon intensity by $0.2022 \%$, and the proportion of the tertiary industry in GDP increasing by $1 \%$ will reduce carbon intensity by $1.3732 \%$.

\subsection{Discussion}

The aforementioned empirical results show that the impact of financial development on carbon emissions intensity does not indicate a simple linear relationship; changes occur in line with the threshold effect of the level of economic development. When the level of economic development is relatively low and per capita GDP is lower than the threshold value of RMB 37,410, the industrial structure tends to be based on high energy consumption and high pollution industries, and so the bank loans will mainly flow to these industries [27,28]. At this stage, the expansion of financial scale will increase carbon intensity. Meanwhile, when the economy develops to a certain degree so that per capita GDP exceeds the threshold value of RMB 37,410, the industrial structure will prioritize the service and high-tech industries, which feature low energy consumption and low pollution. When this occurs, bank loans will flow into these industries. Considering that the energy efficiency of non-state enterprises is higher than that of state-owned enterprises [29,30], while the loans to state-owned enterprise in China are much higher than those to the non-state-owned enterprises, the expansion of financial scale will also increase carbon intensity at this stage, while the promotion effect will attenuate 
compared to that seen in the previous stage. When the level of economic development is relatively low and per capita GDP is lower than the threshold value of RMB 37,410, although the enhancement of financial efficiency will promote the proportion of non-state financial loan in all loans, the industrial structure will be based on high energy consumption and high pollution industries, and so bank loans will mainly flow to those industries. At this stage, the enhancement of financial efficiency will increase carbon intensity. However, when the economy develops to a certain level where per capita GDP exceeds the threshold value of RMB 37,410, the industrial structure will prioritize service and high-tech industries, both of which are characterized by low energy consumption and low pollution, and so bank loans will flow to those industries. Considering that the energy efficiency of the non-state enterprises is higher than that of the state-owned enterprises, the increase of the share of the non-state-owned enterprises in the service and high-tech industries will gradually reduce carbon intensity [31].

We can also see that the per capita GDP of the provinces in the eastern coastal areas of China exceeds the threshold value, and so the decision-making departments of these areas should design effective financial policies that can support the non-state-owned enterprises [32]. In this way, they could create a positive interaction mechanism between financial development and carbon intensity. However, for the central and western areas of China, per capita GDP is less than the threshold value, and so the reasonable path in reducing the carbon intensity would be to become fully aware of the characteristics of the local industrial structure and design effective plans of regional industrial transition [33]. Meanwhile, they should also increase environmental awareness among financial institutions, so as to promote the decrease of the carbon intensity [34].

\section{Conclusions and Policy Suggestions}

We used the panel data from 2005 to 2012 to measure carbon emissions in various provinces in China based on the IPCC National Greenhouse Gas Emission Inventory Guidebook. On this basis, we tested the relationship between carbon intensity and the two indicators of financial development, namelyfinancial scale and financial efficiency, using the threshold model. We derived three key results as follows: (1) the relationships among carbon intensity, financial scale and financial efficiency are near simple linear, and they are more inclined to a piece-wise function with per capita GDP as a threshold variable that divides partition intervals. When per capita GDP is at a low level, the expansion of financial scale and the enhancement of financial efficiency will increase carbon intensity. When per capita GDP exceeds the threshold value, the expansion of financial scale will also increase carbon intensity, but this promotion effect will be weaker in the high zone, and the enhancement of financial efficiency will cause reduce carbon intensity. (2) Most of the provinces with per capita GDP greater than the threshold value (RMB 37,410) are located in the eastern coastal areas of China, whereas most of the provinces with per capita GDP less than the threshold value are located in the central and western areas of China. (3) Increasing the level of openness and improving the industrial structure have significant positive effect on carbon intensity.

Based on the aforementioned empirical results, we should consider the following aspects by which to further reduce carbon intensity further: (1) The development style should be modified so as to focus on efficiency improvement rather than scale expansion; this modification is in keeping with a shift from the tendency of "aristocratic" in the past to the direction of "civilian" [35]. It is necessary to establish an effective credit mechanism for non-state-owned enterprises and develop financial products suitable for the non-state-owned enterprises. (2) We should accelerate the adjustment and upgrading of industrial structure, and continuously optimize the industrial structure and product structure of the heavy chemical industry; concurrently, it should enhance the proportion of high-tech industries and modern service industries in the national economy. (3) We should accelerate the pace of openness, while concurrently optimizing the open structure. It will be important to screen foreign investment and take advantage of international markets and international resources to introduce more advanced low-carbon industries and low-carbon technology; these steps are critical to bring about the win-win situation of concurrent economic development and energy conservation. 
Acknowledgments: This paper is the stage achievement of National Nature Science Foundation Project (71303029), Liaoning province Social Science Fund Project (L13DGL033). The author is grateful for the support of the National Nature Science Foundation and Liaoning province Social Science Foundation. The contents of this paper are solely the responsibility of the authors and do not represent the official views of the aforementioned institutes and funding agencies.

Author Contributions: Xiongfeng Pan designed the research; Xiaoxue Peng and Qing Liu performed research and analyzed the data; Xiongfeng Pan and Yaobo Yan wrote the paper. All authors read and approved the final manuscript.

Conflicts of Interest: The authors declare no conflict of interest.

\section{References}

1. Miomir, J.; Ljiljana, K.; Aleksandra, D.; Vladimir, K. The Impact of Agro-Economic Factors on GHG Emissions: Evidence from European Developing and Advanced Economies. Sustainability 2015, 7, 16290-16310.

2. Vallati, A.; Grignaffini, S.; Romagna, M. A New Method to Energy Saving in a Micro Grid. Sustainability 2015, 7, 13904-13919. [CrossRef]

3. Knight, K.W.; Schor, J.B. Economic Growth and Climate Change: A Cross-National Analysis of Territorial and Consumption-Based Carbon Emissions in High-Income Countries. Sustainability 2014, 6, 3722-3731. [CrossRef]

4. Tamazian, A.; Chousa, J.P.; Vadlamannati, C. Dose Higher Economic and Financial Development Lead to Enviromental Degradation: Evidence from the BRIC Countries. Energy Policy 2009, 37, 246-253. [CrossRef]

5. Tamazian, A.; Rao, B.B. A Model of Growth and Finance: FIML Estimates for India. Energy Econ. 2010, 32, 137-145. [CrossRef]

6. Sadorsky, P. Financial Development and Energy Consumption in Central and Eastern European Frontier Economies. Energ. Pol. 2011, 39, 999-1006. [CrossRef]

7. Shahbaz, M.; Hye, Q.M.A.; Tiwari, A.K. Economic Growth, Energy Consumption, Financial Development, International Trade and $\mathrm{CO}_{2}$ Emissions in Indonesia. Renew. Sustain. Energy Rev. 2013, 25, 109-121. [CrossRef]

8. Shahbaz, M.; Solarin, S.A.; Mahmood, H.; Arouri, M. Does Financial Development Reduce $\mathrm{CO}_{2}$ Emissions in Malaysian Economy? A Time Series Analysis. Econ. Model. 2013, 35, 145-152. [CrossRef]

9. Omri, A. $\mathrm{CO}_{2}$ Emissions, Energy Consumption and Economic Growth Nexus in MENA Countries: Evidence from Simultaneous Equations Models. Energy Econ. 2013, 40, 657-664. [CrossRef]

10. Boutabba, M.A. The Impact of Financial Development, Income, Energy and Trade on Carbon Emissions: Evidence from the Indian Economy. Econ. Model. 2014, 40, 33-41. [CrossRef]

11. Ziaei, S.M. Effects of Financial Development Indicators on Energy Consumption and $\mathrm{CO}_{2}$ Emission of European, East Asian and Oceania countries. Renew. Sustain. Energy Rev. 2015, 42, 752-759. [CrossRef]

12. Al-mulali, U.; Che Sab, C.N.B. The Impact of Energy Consumption and $\mathrm{CO}_{2}$ Emissions on the Economic Growth and Financial Development in the Sub Saharan African Contries. Energy 2012, 39, 180-186. [CrossRef]

13. Zhang, Y. The Impact of Financial Development on Carbon Emissions : An Empirical Analysis in China. Energy Policy 2011, 39, 2197-2203. [CrossRef]

14. Salahuddin, M.; Gow, J.; Ozturk, I. Is the Long-run Relationship between Economic Growth, Electricity Consumption, Carbon Dioxide Emissions and Financial Development in Gulf Cooperation Council Countries robust? Renew. Sustain. Energy Rev. 2015, 51, 317-326. [CrossRef]

15. Abbasi, F.; Riaz, K. CO $\mathrm{CO}_{2}$ Emissions and Financial Development in an Emerging Economy: An Augmented VAR Approach. Energy Policy 2016, 90, 102-114. [CrossRef]

16. Hansen, B.E. Threshold Effects in Non-dynamic Panels: Estimation, Testing, and Inference. J. Econ. 1993, 93, 345-368. [CrossRef]

17. Zhang, N.; Wei, X. Dynamic Total Factor Carbon Emissions Performance Changes in the Chinese Transportation Industry. Appl. Energy 2015, 146, 409-420. [CrossRef]

18. Zhang, N.; Zhou, P.; Kung, C. Total-factor Carbon Emission Performance of the Chinese Transportation Industry: A Bootstrapped Non-radial Malmquist Index Analysis. Renew. Sustain. Energy Rev. 2015, 41, 584-593. [CrossRef]

19. Li, J.; Wei, P. Financial Development and Total Factor Productivity Growth: Empirical Research Based on China's Provincial Panel Data. Econ. Theory Bus. Manag. 2015, 35, 47-64. 
20. Zhao, Y.; Lei, D. Financial Development and Economic Growth: Productivity Promotion versus Capital Formation. J. World Econ. 2010, 33, 37-50.

21. Pan, X.; Yang, Y. Research on Interactive Relationship between Foreign Trade and Carbon Emission: Based on Simultaneous Equation Model. Oper. Res. Manag. Sci. 2013, 01, 132-137.

22. Zhang, N.; Choi, Y. Environmental Energy Efficiency of China's Regional Economies: A Non-oriented Slacks-based Measure Approach. Soc. Sci. J. 2013, 50, 225-234. [CrossRef]

23. Liu, L.; Liang, Q.; Wang, Q. Accounting for China's Regional Carbon Emissions in 2002 and 2007: Production-based versus Consumption-based Principles. J. Clean Prod. 2015, 103, 384-392. [CrossRef]

24. Huang, G.; Ouyang, X.; Yao, X. Dynamics of China's regional carbon emissions under gradient economic development mode. Ecol. Indic. 2015, 51, 197-204. [CrossRef]

25. Pesaran, M.H. General Diagnostic Tests for Cross Section Dependence in Panels; Cambridge Working Papers in Economics, No. 0435; University of Cambridge: Cambridge, UK, 2004.

26. Pesaran, M.H. A Simple Panel Unit Root Test in the Presence of Cross-section Dependence. J. Appl. Econ. 2007, 22, 265-312. [CrossRef]

27. Yang, Y. Impact of Non-state Economic Sector on China's Industrial Enterprises Technical Efficiency. Econ. Res. J. 1998, 12, 29-35.

28. Luo, X. The Effects of Privatization on Industrial Performance in Chinese Economic Transition-Analysis of the 2001 National Industrial Census data. Econ. Res. J. 2004, 8, 16-26.

29. Zhang, N.; Choi, Y. Total-factor Carbon Emission Performance of Fossil Fuel Power Plants in China: A Metafrontier Non-radial Malmquist Index Analysis. Energy Econ. 2013, 40, 549-559.

30. Zhang, N.; Kong, F.; Choi, Y.; Zhou, P. The Effect of Size-control Policy on Unified Energy and Carbon Efficiency for Chinese Fossil Fuel Power Plants. Energy Policy 2014, 70, 193-200. [CrossRef]

31. Guo, W.; Sun, T.; Dai, H. Effect of Polution Structure Change on Cabon Emission in China. Sustainability 2016, 8, 225-244. [CrossRef]

32. Liu, Y.; Xiao, H.; Zhang, N. Industrial Carbon Emissions of China's Region: A Spatial Econometric Analysis. Sustainbility 2016, 8, 210-223. [CrossRef]

33. Zhang, X.; Karplus, V.; Qi, T.; Zhang, D.; He, J. Carbon Emissions in China: How Far Can New Efforts Bend the Curve? Energy Econ. 2016, 54, 388-395. [CrossRef]

34. Wang, Q.; Chen, X. Energy Policies for Managing China's Carbon Emission. Renew. Sustain. Energy Rev. 2015, 50, 470-479. [CrossRef]

35. Fang, J. Ownership, Institutional Environment and Capital Allocation. Econ. Res. J. 2007, 12, 82-92. 